\title{
Hydrogels for in situ encapsulation of biomimetic membrane arrays
}

Ibragimova, Sania; Jensen, Karin Bagger Stibius; Szewczykowski, Piotr Przemyslaw; Perry, Mark; Bohr, Henrik; Helix Nielsen, Claus

\section{Published in:}

Polymers for Advanced Technologies

Link to article, DOI:

10.1002/pat.1850

Publication date:

2012

Document Version

Early version, also known as pre-print

Link back to DTU Orbit

Citation (APA):

lbragimova, S., Jensen, K. B. S., Szewczykowski, P. P., Perry, M., Bohr, H., \& Helix Nielsen, C. (2012). Hydrogels for in situ encapsulation of biomimetic membrane arrays. Polymers for Advanced Technologies, 23, 182-189. https://doi.org/10.1002/pat.1850

\section{General rights}

Copyright and moral rights for the publications made accessible in the public portal are retained by the authors and/or other copyright owners and it is a condition of accessing publications that users recognise and abide by the legal requirements associated with these rights.

- Users may download and print one copy of any publication from the public portal for the purpose of private study or research.

- You may not further distribute the material or use it for any profit-making activity or commercial gain

- You may freely distribute the URL identifying the publication in the public portal 


\section{(W) WILEY}

JOHN WILEY \& SONS, LTD., THE ATRIUM, SOUTHERN GATE, CHICHESTER P019 8SQ, UK

\section{*** PROOF OF YOUR ARTICLE ATTACHED, PLEASE READ CAREFULLY ***}

After receipt of your corrections your article will be published initially within the online version of the journal.

\section{PLEASE NOTE THAT THE PROMPT RETURN OF YOUR PROOF CORRECTIONS WILL ENSURE THAT THERE ARE NO UNNECESSARY DELAYS IN THE PUBLICATION OF YOUR ARTICLE}

\section{READ PROOFS CAREFULLY}

\section{ONCE PUBLISHED ONLINE OR IN PRINT IT IS NOT POSSIBLE TO MAKE ANY FURTHER CORRECTIONS TO YOUR ARTICLE}

B This will be your only chance to correct your proof

B Please note that the volume and page numbers shown on the proofs are for position only

ANSWER ALL QUERIES ON PROOFS (Queries are attached as the last page of your proof.)

B List all corrections and send back via e-mail to the production contact as detailed in the covering e-mail, or mark all corrections directly on the proofs and send the scanned copy via e-mail. Please do not send corrections by fax or post

\section{CHECK FIGURES AND TABLES CAREFULLY}

B Check sizes, numbering, and orientation of figures

B All images in the PDF are downsampled (reduced to lower resolution and file size) to facilitate Internet delivery. These images will appear at higher resolution and sharpness in the printed article

B Review figure legends to ensure that they are complete

Check all tables. Review layout, titles, and footnotes

\section{COMPLETE COPYRIGHT TRANSFER AGREEMENT (CTA) if you have not already signed one}

Please send a scanned signed copy with your proofs by e-mail.Your article cannot be published unless we we have received the signed CTA

\section{$\square$ AUTHOR SERVICES}

B If you have registered this article in Wiley-Blackwell Author Services, the article's status will be updated shortly after you have returned your proof corrections (you will also receive an e-mail alert if you have opted to receive them). You are entitled to free access to the PDF from Author Services when your article is published online. This free access is considered your PDF offprint, and you will only have access from within Author Services; you will not be sent a PDF. You may also nominate up to 10 colleagues for free access. All accesses from Author Services count towards the usage of your article. For options to order print copies or additional electronic access, please see below.

\section{OFFPRINTS}

B Free access to the final PDF offprint of your article will be available via Author Services only. Please therefore sign up for Author Services if you would like to access your article PDF offprint and enjoy the many other benefits the service offers

\section{Additional reprint and journal issue purchases}

B Should you wish to purchase additional copies of your article, please click on the link and follow the instructions provided: http://offprint.cosprinters.com/cos/bw/

B Corresponding authors are invited to inform their co-authors of the reprint options available.

B Please note that regardless of the form in which they are acquired, reprints should not be resold, nor further disseminated in electronic form, nor deployed in part or in whole in any marketing, promotional or educational contexts without authorization from Wiley. Permissions requests should be directed to mailto: permissionsuk@wiley.com

B For information about 'Pay-Per-View and Article Select' click on the following link: http://www3.interscience.wiley.com/aboutus/ppv-articleselect.htm 


\title{
Hydrogels for in situ encapsulation of biomimetic membrane arrays
}

\section{Sania Ibragimova ${ }^{a, c}$, Karin Stibius ${ }^{a, c}$, Piotr Szewczykowski ${ }^{b}$, Mark Perry $^{c}$, Henrik Bohr ${ }^{\mathrm{a}}$ and Claus Hélix-Nielsen ${ }^{\mathrm{a}, \mathrm{c*}}$}

\begin{abstract}
Hydrogels are hydrophilic, porous polymer networks that can absorb up to thousands of times their own weight in water. They have many potential applications, one of which is the encapsulation of freestanding black lipid membranes (BLMs) for novel separation technologies or biosensor applications. We investigated gels for in situ encapsulation of multiple BLMs formed across apertures in a hydrophobic ethylene tetrafluoroethylene (ETFE) support. The encapsulation gels consisted of networks of poly(ethylene glycol)-dimethacrylate or poly(ethylene glycol)-diacrylate polymerized using either a chemical initiator or a photoinitiator. The hydrogels were studied with regards to volumetric stability, porosity, and water permeability. All hydrogels had pore sizes around $7 \mathrm{~nm}$ with volumetric changes $>\mathbf{2} \%$ upon crosslinking. Photoinitiated hydrogels had a lower hydraulic water permeability compared to chemically initiated hydrogels; however, for all hydrogels the permeability was several-fold higher than the water permeability of conventional reverse osmosis (RO) membranes. Lifetimes of freestanding BLM arrays in gel precursor solutions were short compared to arrays formed in buffer. However, polymerizing (crosslinking) the gel stabilized the membranes and resulted in BLM arrays that remained intact for days. This is a substantial improvement over lifetimes for freestanding BLM arrays. Optical images of the membranes and single channel activity of incorporated gramicidin ion channels showed that the lipid membranes retained their integrity and functionality after encapsulation with hydrogel. Our results show that hydrogel encapsulation is a potential means to provide stability for biomimetic devices based on functional proteins reconstituted in biomimetic membrane arrays. Copyright (C) 2010 John Wiley \& Sons, Ltd.
\end{abstract}

Keywords: biomimetic membrane arrays, encapsulation, hydrogel, stabilization, voltage clamp

\section{INTRODUCTION}

Transmembrane proteins have many functions in biological systems, and act for example as channels, receptors, or transporters. Recently the notion of biomimetic membranes as technological devices incorporating essential features of biological membranes has attracted considerable interest, for recent reviews see Ref. ${ }^{[1-4]}$. Working biomimetic membranes require that the protein must be in its native (functional) conformation. This implies that for transmembrane proteins, the protein must be embedded in a matrix compatible with protein structure and function $^{[5-7]}$. Black lipid membranes (BLMs) formed across single or multi-aperture hydrophobic scaffolds closely resemble the natural environment of membrane spanning proteins. However, freestanding BLMs have notoriously low longevity, which limits many applications, for comprehensive texts on BLMs see Refs. ${ }^{[8,9]}$. A biomimetic membrane working as a sensor/separation device should be stable and typically be able to withstand osmotic/ hydrostatic pressures. This is not compatible with freestanding BLMs.

In order to improve BLM longevity and stability in multiaperture arrays, we investigated the encapsulation of BLMs in an in situ polymerized hydrogel. Hydrogels are hydrophilic polymer networks that can absorb up to thousands of times their dry weight in water ${ }^{[10-12]}$. Hydrogels have been shown to allow transport of water, electrolytes, and possibly proteins depending on the pore size of the hydrogel network ${ }^{[10,13]}$. Recently encapsulation of single freestanding biomimetic membranes has been proven to be a successful approach ${ }^{[13-23]}$. In this work we characterize several hydrogels and show successful hydrogel encapsulation of multiple BLMs formed across an aperture array.

In order for biological membranes to maintain their liquid crystalline state they generally require ambient temperatures between 10 and $40{ }^{\circ} \mathrm{C}^{[24]}$. Although the use of block-copolymers could extend the temperature range for the biomimetic protein matrix per se, the proteins themselves will generally denature

* Correspondence to: C. Hélix-Nielsen, DTU Physics, Fysikvej 309, Building 309, office 138, Technical University of Denmark, DK-2800 Lyngby, Denmark E-mail: Claus.Helix.Nielsen@fysik.dtu.dk

a S. Ibragimova, K. Stibius, H. Bohr, C. Hélix-Nielsen DTU Physics, Technical University of Denmark, Fysikvej 309, Building 309, DK-2800 Kgs. Lyngby, Denmark

b P. Szewczykowski DTU Chemical Engineering, Technical University of Denmark, K DK-2800 Kgs. Lyngby, Denmark

C S. Ibragimova, K. Stibius, M. Perry, C. Hélix-Nielsen

Aquaporin A/S, Ole Maaløes Vej 3, DK-2200 Copenhagen, Denmark

Contract/grant sponsor: MEMBAQ, a Specific Targeted Research Project (STREP), by the European Commission under the Sixth Framework Programme; contract/grant number: NMP4-CT-2006-033234.

Contract/grant sponsor: Danish National Advanced Technology Foundation; contract/grant number: 023-2007-1.

Contract/grant sponsor: Grant to DTU Physics from the Danish National Research Foundation. 
with increased temperatures ${ }^{[25]}$. Thus, a required property for a hydrogel for encapsulating biomimetic membranes is that it is liquid and crosslinkable in situ at room temperature. Poly(ethylene glycol)-di(meth)acrylate (PEG-D(M)A) based hydrogels fulfill this requirement. Amongst other requirements is that the crosslinking process should not result in large gel volume changes as this would destabilize the biomimetic membrane. In addition the porosity of the encapsulating gel should be able to provide sufficient stability while preserving good water and solute permeabilities.

We have studied the encapsulation potential of PEG-1000-DMA and PEG-400-DA hydrogels. In particular, we characterized chemically induced and UV-induced polymerized hydrogels with respect to volumetric stability, water permeability, and porosity. We obtained stable hydrogel encapsulated lipid bilayers with lifetimes of several days in an aperture array with 64 individual BLMs as evidenced by monitoring conductance and capacitance using standard voltage-clamp measurements ${ }^{[26,27]}$. Functionality of the encapsulated BLMs was demonstrated by recording single channel activity of incorporated gramicidin ion channels.

\section{EXPERIMENTAL}

\section{Materials}

Poly(ethylene glycol)-1000-dimethacrylate (PEG-1000-DMA) and poly (ethylene glycol)-400-diacrylate (PEG-400-DA ) were from Polysciences (Warrington, PA, USA). 2 -Hydroxy -2-methyl -1 - phenyl-propan-1-one (Darocur ${ }^{\circledR} 1173$ ) was from Ciba Specialty Chemicals (Basel, Switzerland). $\mathrm{KCl}, \mathrm{HCl}$, 1,4-Piperazinediethanesulfonic acid (PIPES), ethylenediaminetetraacetic acid (EDTA), protease inhibitor cocktail (P2714), sodium hydroxide, $N, N, N^{\prime}, N^{\prime}$-tetramethyle thylenediamine (TEMED), $n$-decane, ethanol, and ammonium persulfate (APS) were from Sigma Aldrich Denmark (Brøndby, Denmark). Multiaperture arrays were fabricated from Tefzel ethylene tetrafluoroethylene (ETFE) LZ200 (DuPont, Detroit, USA). Sheets of cellulose membrane on a propylene support (DSS-RC70PP) were from Alfa Laval (Nakskov, Denmark). For the retention experiments $1 \mathrm{kDa}$ beads were from Merck-Schuchardt (Hohenbrunn, Germany) and 3-35 kDa beads from Fluka (Buchs, Switzerland).

For the encapsulated bilayer experiments, Viton A fluoroelastomer used for the production of rubber chamber-sealing O-rings was from DuPont Fluoropolymers (Detroit, USA). Uncoated 35 and $50 \mathrm{~mm}$ glass-bottom culture dishes were from MatTek (Ashland, MA, USA). 1,2 -diphytanoyl-sn-glycero-3 -phosphocholine (DPhPC) and 1,2 -Diphytanoyl -sn -Glycero -3-phosphoethanol-amine- $N$-acrylate (DPhPE-A) were from Avanti Polar Lipids Inc. (Alabaster, AL, USA) and gramicidin was from Sigma Aldrich Denmark (Brøndby, Denmark).

\section{Methods}

\section{Preparation of hydrogels}

Hydrogels were studied in two experimental configurations (see Fig. 1). For the porosity and water flux characterization, the configuration consisted of a hydrogel sandwiched between a DSS-RC70PP membrane and a partition with an $8 \times 8$ aperture array fabricated from ETFE as previously described ${ }^{[28]}$ (see Fig. 1a). For the BLM encapsulation experiments BLM arrays were formed across the ETFE partitions and subsequently gel encapsulated (see Fig. 1b). The two configurations can be seen as prototypical
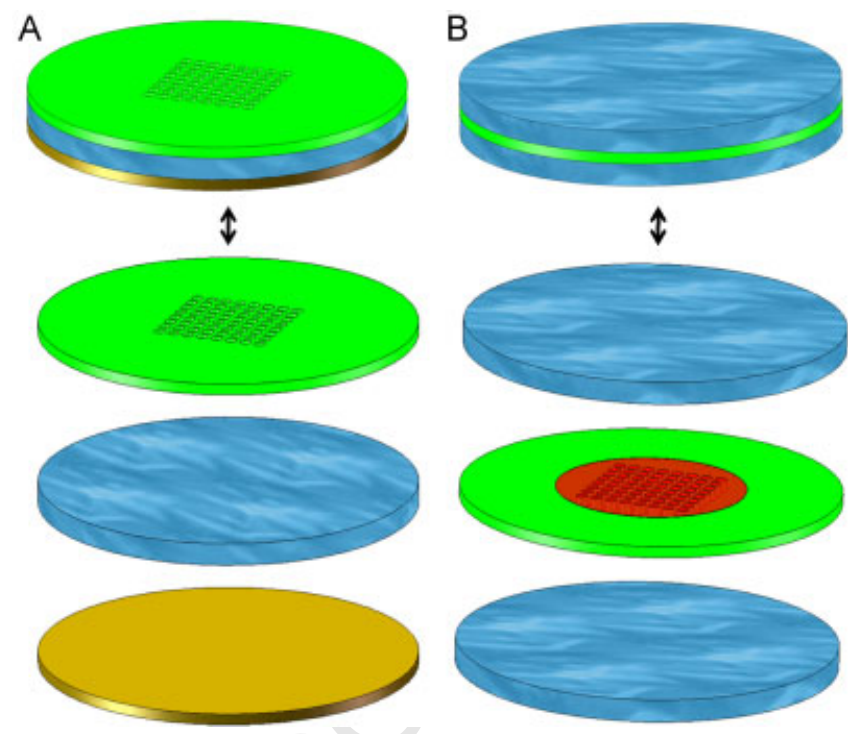

Figure 1. Schematic representations of the hydrogel sandwich and of the hydrogel-encapsulated lipid membrane (closed and exploded views). (a): The sandwich consists of an ETFE partition $ø 21 \mathrm{~mm}$ with an $8 \times 8$ aperture (aperture diameter $300 \mu \mathrm{m}$ ) array (green), a crosslinked hydrogel (blue) and a regenerated cellulose membrane $(\varnothing 21 \mathrm{~mm}$ ) on polypropylene support (brown) positioned with the cellulose side toward the gel and the polypropylene side away from the gel. (b): For BLM encapsulation a BLM (semi-transparent red circular area) is formed across the aperture array in the ETFE partition (green disk) and encapsulated ${ }^{\mathrm{Q} 1}$ by hydrogel on both sides (blue disks). This figure is available in colour online at wileyonlinelibrary.com/journal/pat.

for future applications: a sandwich supported membrane for separation applications where hydrostatic pressures are applied (Fig. 1a.), a free-standing encapsulated membrane for sensor applications, where no (or low) pressures are applied.

For all hydrogels, concentrations of PEG and initiator were selected so that the hydrogels crosslinked within $10 \mathrm{~min}$ of initiation. Table 1 and Fig. 2 present the hydrogels used in this study.

All hydrogel precursor solutions (HPSs) were prepared in a buffer containing $25 \mathrm{mM}$ PIPES, $2 \mathrm{mM}$ EDTA, $0.2 \mathrm{M} \mathrm{KCl}$ and protease inhibitor cocktail in MilliQ water, adjusted to $\mathrm{pH} 6.5$ using $\mathrm{HCl}$.

For photoinitiation, two aqueous HPSs were prepared: a PEG-1000-DMA solution (1000P) containing $65 \mathrm{mM}$ poly(ethylene glycol)-1000-dimethacrylate monomers and $10 \mathrm{mM}$ Darocur1173 photoinitiator and a PEG-400-DA solution (400P) containing

Table 1. The four hydrogel precursor solutions (HPSs) investigated. For details see the Materials and Methods section

\begin{tabular}{|lll|} 
Sample & Polymer & \multicolumn{1}{c|}{ Initiator } \\
\hline $400 \mathrm{P}$ & $\begin{array}{l}\text { PEG-400-DA } \\
100 \mathrm{mM}\end{array}$ & Darocur $5 \mathrm{mM}$ \\
$400 \mathrm{C}$ & & TEMED $15 \mathrm{mM}$, \\
& APS $15 \mathrm{mM}$ \\
$1000 \mathrm{P}$ & PEG-1000-DMA & Darocur $5 \mathrm{mM}$ \\
& $65 \mathrm{mM}$ & TEMED $10 \mathrm{mM}$ \\
$1000 \mathrm{C}$ & & APS $10 \mathrm{mM}$ \\
& &
\end{tabular}

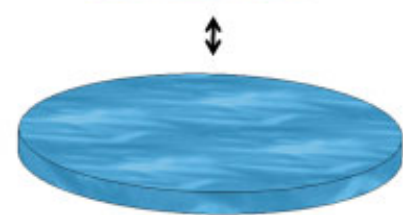


A<smiles>CC(C)CCCC(C)CCCC(C)CCCC(C)CC(=O)OC[C@H](COP([O])(=O)OCC[N+](C)(C)C)OC(=O)CC(C)CCCC(C)CCCC(C)CCCC(C)C</smiles>

B<smiles>C=CC(=O)NCCOP(=O)([O-])OCC([CH2-])COC(=O)CC(C)CCCC(C)CCCC(C)CCC(C)CCCC(C)CCCC(C)C</smiles>

C<smiles>C=C(C)C(=O)OCCOC(C)(C)C(=O)C(=C)C</smiles>

D<smiles>C=CC(=O)OCCC(C)OC(=O)C=C</smiles>

61

62

63

64

65

66

67

68

69

70

71

72

73

74

75

76

77

78

79

80

81

82

83

84

85 $0.5 \mathrm{mg} / \mathrm{ml}$ in Millio water was passed through the hydrogel sandwich using a homemade water flux measurement setup.

Size exclusion chromatography was performed using a 717PLUS Autosampler configured with a $600 \mathrm{E}$ controller and a 410 Refractive Index Detector from Waters Corporation (Waters, Milford, MA, USA). Measurements were done using Waters Ultrahydrogel $2506 \mu \mathrm{m} 7.8 \times 300 \mathrm{~mm}^{2} \mathrm{GPC}$ column with MilliQ water as eluent at a flow rate of $0.6 \mathrm{ml} \mathrm{min}^{-1}$ and a sample injection volume of $40 \mu \mathrm{l}$. Three consecutive permeates for each hydrogel sandwich sample were collected and results reported using the third permeate chromatogram as it was identical to the second permeate chromatogram indicating that a steady-state was reached.

\section{Water permeability measurements}

The hydrogel sandwich was placed in a homemade flow unit cell. The time $t$ needed to collect a given volume $V$ of permeate 
(approximately $1 \mathrm{ml}$ ) was measured at 1, 1.5, and 2 bars of the feed pressure $P$. The water flux $J_{\mathrm{w}}$ was calculated as $J_{\mathrm{w}}=\frac{V}{t V_{1 w}}$, where $V_{w}$ is the partial molar volume of water $\left(1.8 \times 10^{-5} \mathrm{~m}^{3} \cdot \mathrm{mol}^{-\frac{t q}{t}}\right)$, The hydraulic permeability $L_{p}\left[\mathrm{~m} \cdot \mathrm{s}^{-1} \cdot \mathrm{Pa}^{-1}\right]$ and the diffusional permeability $P_{\mathrm{w}}[\mathrm{m} / \mathrm{s}]$ of the membrane were calculated from Equation (2), where $R$ is the gas constant $\left(8.3145 \mathrm{~m}^{3} \cdot \mathrm{Pa} \cdot \mathrm{K}^{-1} \cdot \mathrm{mol}^{-1}\right)$ and $T$ is the temperature.

$$
L_{\mathrm{p}}=\frac{J_{\mathrm{w}} V_{\mathrm{w}}}{\Delta P}, \quad P_{\mathrm{w}}=\frac{J_{\mathrm{w}} R T}{\Delta P}=\frac{L_{\mathrm{p}} R T}{V_{\mathrm{w}}}
$$

Formation of hydrogel-encapsulated BLMs across multi-aperture ETFE partitions

$2 \mathrm{ml} \mathrm{DPhPC}$ or $1 \mathrm{ml}$ DPhPE-A in chloroform $\left(10 \mathrm{mg} \mathrm{ml}^{-1}\right)$ was placed under nitrogen flow to evaporate the solvent and the dry lipid films were rehydrated in $400 \mu \mathrm{l}$ and $193 \mu \mathrm{l}$-decane respectively to a final concentration of $59 \mathrm{mM}$. The lipid solutions were prepared 1 day prior to use and stored at $-20^{\circ} \mathrm{C}$.

Briefly, the experimental chamber for bilayer formation consisted of an open top compartment and an open bottom compartment ( 35 and $50 \mathrm{~mm}$ culture dishes, respectively). The glass cover slip of the $35 \mathrm{~mm}$ glass-bottom dish was replaced with an ETFE partition with an $8 \times 8$ aperture array by first removing the cover slip by adding $0.5 \mathrm{ml}$-heptane to the dishes for $10 \mathrm{~min}$, and then gluing the ETFE LZ200 partition array on the dish using silicone-based glue (Dow Corning, Midland, MI, USA). A Viton ring was placed between the two Petri dishes to create two independently accessible compartments and a reusable aluminium holder was used to clamp the upper dish/viton ring/ lower dish sandwich together.

The bottom and top compartments were filled with $4.5 \mathrm{ml}$ of a HPS. The experimental chamber was placed in a Faraday cage and $\mathrm{Ag} / \mathrm{AgCl}$ electrodes were placed in each compartment. $2 \mu \mathrm{l}$ of the lipid solution was deposited over the apertures using a Pasteur pipette to form BLMs, simultaneously monitoring the current between the electrodes. To facilitate bilayer thinning, an air bubble was created at the tip of the Pasteur pipette and swept gently across the entire ETFE partition array.

When all apertures were filled with lipid membranes, an electrical seal was obtained and the capacitance (C) and conductance $(G)$ of the formed membrane array could be measured by applying triangular $\left(10 \mathrm{mV}_{\mathrm{pp}}\right)$ and rectangular $\left(10 \mathrm{mV}_{\mathrm{pp}}\right)$ voltage clamp waveforms, respectively. Membrane capacitance values $\left(C=I(\mathrm{~d} U / \mathrm{d} t)^{-1}\right.$ was determined by measuring the peak-to-peak amplitude of the square-shaped response signal, while the membrane conductance $(G=I / U)$ was determined from the post-transient steady-state amplitudes. Thinning of the array membranes was evidenced electrically as increase in $C$ and optically with a light microscope with the appearance of Plateau-Gibbs borders. As the measurements recorded $C$ and $G$ from the entire array, rupture of even a single membrane in the array was evident as a complete loss of the electrical seal $(G \approx 0 \Omega)$. For details on chamber assembly and multi-array BLM monitoring and characterization see Ref. ${ }^{[26,27,29]}$.

After BLM formation, encapsulation in X1000P was performed by UV irradiation of the $1000 \mathrm{P}$ solution with a $100 \mathrm{~W}$ EXFO Omnicure1000 UV-lamp (EXFO Photonic Solutions Inc, Canada). Irradiation was performed at $2 \%$ of the lamp intensity at a lamp distance of $3 \mathrm{~cm}$ from the ETFE partition, and with a total UV irradiation time of 15 min divided into intervals of 5 min UV

irradiation followed by 5 min intervals without UV irradiation. The experimental chamber was covered in order to minimize evaporation.

Incorporation of the channel forming peptide gramicidin into lipid membrane arrays was carried out by drying $120 \mathrm{nM}$ gramicidin in ethanol under a nitrogen flow and re-dissolving to a final concentration of $3 \mathrm{nM}$ in the bilayer forming solution. The gramicidin-containing multiple BLMs were encapsulated in $\mathrm{X} 1000 \mathrm{P}$ as described above with buffer adjusted to $1 \mathrm{M} \mathrm{KCl}$ as electrolyte. For single channel recordings, a $60 \mathrm{mV} \mathrm{DC}$ potential was applied across the membranes and current traces were acquired at $1 \mathrm{kHz}$ using a patch-clamp amplifier (A-M Systems, Sequim, WA, USA) and filtered through a low pass Bessel filter (Frequency Devices, IL, USA) with a $10 \mathrm{~Hz}$ cutoff.

\section{RESULTS AND DISCUSSION}

We first examined material properties of the selected hydrogels relevant for the use of hydrogels as an encapsulation material for biomimetic membranes. Then we proceeded by demonstrating that crosslinked hydrogels can be used for in situ encapsulation of biomimetic membranes formed across multi-aperture arrays.

\section{Hydrogel material properties}

Volumetric stability

Amongst the requirements for an encapsulating hydrogel is that it should not undergo large volume changes upon crosslinking as the expanding gel would exert a pressure on the lipid membrane and rupture it. We observed that the HPSs containing PEG-400-DA or PEG-1000-DMA only shrank slightly upon crosslinking $\left(\Delta V_{X}<1.1 \%\right)$ (see Table 2$)$. Bringing the crosslinked gels from room temperature to $4{ }^{\circ} \mathrm{C}$ resulted in further shrinkage $\left(\Delta V_{X}<2.0 \%\right)$, which exceeded the shrinkage due to crosslinking per se, but was still very small. The low degree of shrinkage upon gelation and temperature change is an attractive property as it makes it feasible to encapsulate biomimetic membranes and store them at $4{ }^{\circ} \mathrm{C}$, thus minimizing evaporation and degradation.

\section{Polymer mesh size}

The hydrogel pore sizes were characterized by passing an aqueous feed solution containing a mixture of PEG beads of various sizes at 1 bar through each assembled hydrogel sandwich (see Fig. 1a).

The permeate analysis is shown in Fig. 3. Figure 3a shows the permeate profiles for the feed, for the hydrogel sandwiches

Table 2. Volumetric stability of HPSs upon crosslinking. Shrinkage of each HPS upon crosslinking is expressed in percent of the volume of the HPS and upon cooling in percent of the volume of the gel. All values are given as mean $\pm s d$ $(n=3)$

\begin{tabular}{|llc|} 
Hydrogel & $\Delta V_{X}(\%)$ & $\Delta V_{X, \text { Cool }}(\%)$ \\
\hline X1000P & $-0.5 \pm 0.4$ & $-1.0 \pm 0.4$ \\
X1000C & $-0.6 \pm 0.2$ & $-1.3 \pm 0.4$ \\
X400P & $-0.8 \pm 0.4$ & $-0.5 \pm 0.4$ \\
X400C & $-0.4 \pm 0.1$ & $-1.4 \pm 0.6$ \\
\hline
\end{tabular}



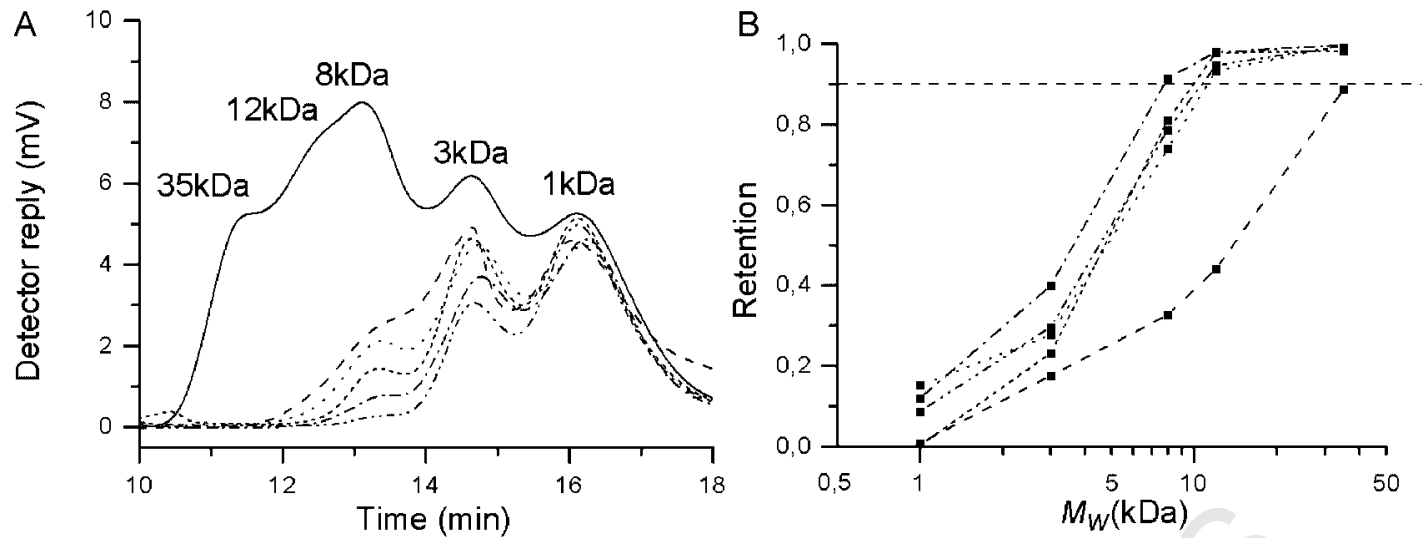

Figure 3. Hydrogel retention measurements. (a): Size-exclusion chromatograms of the feed (black line), the permeates through DSS-RC70PP(- - -), X1000C $(\cdots)$, X1000P $(-\cdots-$.$) , X400P (\cdots-\cdots)$, and X400C (…) hydrogel sandwiches. The bead size corresponding to each peak is indicated. (b): Retention curves for the data in (a) showing the retention for each PEG molecular weight. The cut-off level is defined as a $90 \%$ rejection level and indicated by the dashed line.

analyzed, and for the PEG bead solution when permeated through DSS-RC70PP alone. Larger beads are able to pass through the DSS-RC70PP membrane than through the hydrogel sandwich, which indicates that the bead retention $R$ observed in the hydrogel sandwiches is caused by the hydrogels. Figure $3 \mathrm{~b}$ shows $R$ for the hydrogel sandwiches as a function of molecular weight:

$$
R=\frac{c_{\mathrm{f}}-c_{\mathrm{p}}}{c_{\mathrm{f}}}
$$

where $c_{f}$ is the detected peak height of the feed and $c_{p}$ is the detected peak height of the permeate for each PEG bead molecular weight. The cut-off size, defined as the bead molecular weight for which $90 \%$ of the beads are retained by the sandwich $^{[30]}$, was around $10 \mathrm{kDa}$ for all gels and about three times lower than for the DSS-RC70PP membrane (>30 kDa). A $10 \mathrm{kDa}$ bead size corresponds to a bead hydrodynamic diameter of about $7 \mathrm{~nm}^{[31]}$. This is similar to the mesh-size of PEG-1000-DMA reported previously ${ }^{[13]}$. X1000P had a marginally smaller cut-off diameter than the other gels. Thus both crosslinked PEG-400-DA and PEG-1000-DMA have nanoscale mesh structures suitable for biomimetic membrane support.

\section{Water permeability}

In order to ascertain whether the nanoscale mesh hydrogels would impede solute and solvent flux across the membrane, we performed water flux measurements on the hydrogel sandwiches and the results are summarized in Table 3. Fluxes were compared to the flux through DSS-RC70PP membrane alone and flux through an 'empty' sandwich consisting of a perforated ETFE disk on top of a disk of DSS-RC70PP membrane. The DSS-RC70PP membrane had a mean $L_{p}$ value of $1.65 \times 10^{-10} \mathrm{~m} \cdot \mathrm{s}^{-1} \cdot \mathrm{Pa}^{-1}$, not significantly different from the mean value of $1.52 \times 10^{-10} \mathrm{~m} \cdot \mathrm{s}^{-1} \cdot \mathrm{Pa}^{-1}$ measured when the perforated ETFE partition was put on top of the cellulose. The presence of crosslinked hydrogel reduced $L_{p}$ for all hydrogels investigated (see Table 3). The reduction was larger for photoinitiated gels than for chemically initiated gels with no correlation between hydrogel PEG chain length/mesh size and flux reduction. The photoinitiated gels contain the Darocur 1173 initiator which is hydrophobic (c.f. CIBA
Darocur 1173 datasheet), and the reduction in water permeability may be due to photoinitiated gels having residual amounts of initiator left in contrast to the chemically initiated gels tested. The highest gel $L_{p}$ was found for X400C $\left(1.06 \times 10^{-10} \mathrm{~m} \cdot \mathrm{s}^{-1} \cdot \mathrm{Pa}^{-1}\right)$, i.e. reduced to about $60 \%$ of the $L_{p}$ of the empty sandwich whereas the lowest $L_{p}=3.4 \times 10^{-11} \mathrm{~m} \cdot \mathrm{s}^{-1} \cdot \mathrm{Pa}^{-1}$ was found for X400P. A typical reverse osmosis (RO) membrane flux is about $12 \mathrm{~L} \cdot \mathrm{m}^{2} \cdot \mathrm{h}^{-1}$ operated at $600 \mathrm{kPa}$ (brackish water feed ${ }^{[32]}$ corresponding to $L_{p}=5.6 \times 10^{-12} \mathrm{~m} \cdot \mathrm{s}^{-1} \cdot \mathrm{Pa}^{-1}$. Thus all hydrogels tested have water permeabilities at least five-fold higher than the permeability for a typical RO membrane. The hydrogels do therefore not constitute the limiting factor in biomimetic separation devices, allowing the overall device permeability (and selectivity) properties to be determined by the biomimetic membrane per se.

\section{Hydrogels as encapsulation materials}

Having established that the PEG-DMA- and PEG-DA-based hydrogels have mesh size, water flux, and volumetric stability parameters compatible with their use as encapsulation material we now investigated in situ encapsulation of biomimetic lipid

Table 3. Water permeability data. For each sample flux was measured at 1, 1.5, and 2 bars and the water permeability $L_{p}$ was obtained from a linear fit to the flux-pressure relationships with $r>0.99$. The effective sample area was $3.46 \mathrm{~cm}^{2}$. All values given as mean $\pm \mathrm{sd}(n=3)$

\begin{tabular}{lcc|} 
Sample & $\begin{array}{c}L_{\mathrm{p}} \\
\left(10^{-12} \mathrm{~m} \cdot \mathrm{s}^{-1} \cdot \mathrm{Pa}^{-1}\right)\end{array}$ & $\begin{array}{c}P_{\mathrm{w}} \\
\left(\mathrm{cm} \cdot \mathrm{s}^{-1}\right)\end{array}$ \\
\hline Cellulose & $165 \pm 18$ & $2.28 \pm 0.25$ \\
Cellulose + ETFE & $152 \pm 24$ & $2.09 \pm 0.33$ \\
X1000P & $39 \pm 7$ & $0.53 \pm 0.10$ \\
X1000C & $55 \pm 19$ & $0.76 \pm 0.27$ \\
X400P & $34 \pm 14$ & $0.46 \pm 0.19$ \\
X400C & $106 \pm 41$ & $1.46 \pm 0.56$ \\
RO* & 5.6 & 0.08 \\
* Based on 12 $\mathrm{L} \mathrm{m}^{-2} \mathrm{~h}^{-1}$ at $600 \mathrm{kPa}$, see Ref. ${ }^{[32]}$. \\
\hline
\end{tabular}


membranes. We characterized lipid membrane lifetimes in hydrogel precursor solution and lifetimes and membrane characteristics of hydrogel-encapsulated lipid membranes. We selected photoinitiated hydrogels, as the initiator can be added directly to the HPS yielding a homogeneous distribution of initiator. Also UV irradiation yielded precise control of the time point at which the polymerization reaction began.

\section{Effects of HPS on BLM formation and stability}

We tested both $n$-decane containing DPhPC and DPhPE-A lipid bilayers. DPhPC is a commonly used lipid for BLMs ${ }^{[1]}$. DPhPE-A contains an acrylate group which has the potential to covalently link to the acrylate group of PEG-1000-DMA or PEG-400-DA upon crosslinking.

Free-standing DPhPC and DPhPE-A BLMs in buffer had lifetimes up to $20 \mathrm{hr}$ for DPhPC and up to $19 \mathrm{hr}$ for DPhPE-A (see Table 5). Adding polymer to the buffer resulted in BLMs with lifetimes up to $18 \mathrm{hr}$ for DPhPC and up to $14 \mathrm{hr}$ for DPhPE-A (see Table 4). When both photoinitiator and polymer were present in the HPS, stability was reduced significantly with BLM lifetimes up to $139 \mathrm{~min}$.

In order to identify whether the reduced BLM stability was due to specific interactions between photoinitiator and BLM, we investigated DPhPE-A membrane formation in the presence of photoinitiator alone in buffer where we obtained lifetimes ranging from 9 to $139 \mathrm{~min}$. The minimum DPhPE-A membrane lifetime was substantially larger than the minimum lifetimes (seconds) observed for solutions containing PEG-based polymers with or without initiator. From this we conclude that the initiator per se does not compromise BLM formation, but it affects BLM lifetime. Thus the pre-encapsulation step, where both polymer and initiator are present, generally tends to destabilize the BLMs.

\section{Stability of encapsulated BLMs}

A sufficient minimum membrane lifetime is more critical than a maximum membrane lifetime as the membranes need to survive long enough in the HPS to become encapsulated. We selected the 1000P HPS for encapsulating BLMs, as we observed a higher minimum lifetime (albeit still $<1 \mathrm{~min}$ ) for membranes in $1000 \mathrm{P}$ than in the 400P HPS.

We then encapsulated DPhPE-A and DPhPC with 1000P using UV-initiation started as soon as the membrane array was formed. The presence of X1000P seemed to "freeze" the membrane array protecting it from rupture. Once membranes were encapsulated, they all survived more than 1 day. Although several DPhPC membrane arrays ruptured during crosslinking we were able to have a DPhPC membrane array surviving in X1000P for more than a day (see Table 5), which is 12 times longer than the maximum lifetime we obtained for DPhPC membrane arrays in 1000 .

The DPhPE-A membranes generally performed better than DPhPC membranes, with lifetimes ranging from $47 \mathrm{hr}$ to 3.6 days in $\mathrm{X} 1000 \mathrm{P}$ (compared to $1 \mathrm{~min}$ in 1000P). Encapsulated membrane arrays were stored at room temperature with no visible degradation. The hydrogel seemed to stabilize these membranes considerably, which suggested that the gel was covalently linking to the membranes via the headgroup acrylate moiety. Alternatively, the observed stabilizing effect could be due to DPhPE-A lipids stabilized by crosslinking the lipid headgroups with each other and not due to the hydrogel. We

Table 4. Lifetimes of DPhPC and DPhPE-A lipid membranes in hydrogel precursor solution components. DPhPC and DPhPE-A bilayers were formed in HPS across an ETFE partition with an $8 \times 8$ rectangular aperture ( $300 \mu \mathrm{m}$ diameter) array. The minimum and maximum observed lifetimes of membranes with $\mathrm{C}>2000 \mathrm{pF}$ are given. For each HPS composition tested, the success rate (success = survival of the membrane for at least $5 \mathrm{~min}$ ) for these membranes is indicated as the number of successful membranes out of the total number of membranes formed

\begin{tabular}{|rlccl|}
\multicolumn{1}{ll}{ HPS } & Lipid & $t_{\min }(\min )$ & $t_{\max }(\min )$ & $\left.S_{(t>5} \min \right)$ \\
\hline 1000 & DPhPC & 0.05 & 189 & $6 / 32$ \\
1000 & DPhPE-A & 1 & 835 & $14 / 16$ \\
$1000 \mathrm{P}$ & DPhPC & 0.08 & 139 & $2 / 7$ \\
$1000 \mathrm{P}$ & DPhPE-A & 0.03 & 1 & $0 / 9$ \\
400 & DPhPC & 0.03 & 1135 & $3 / 7$ \\
400 & DPhPE-A & 0.03 & 28 & $4 / 25$ \\
$400 \mathrm{P}$ & DPhPC & 0.02 & 9 & $1 / 4$ \\
$400 \mathrm{P}$ & DPhPE-A & 0.02 & 32 & $1 / 6$ \\
$\mathrm{P}$ & DPhPE-A & 9 & 139 & $3 / 3$ \\
\hline
\end{tabular}

therefore analyzed DPhPE-A BLM stability in Darocur1173 solution alone exposed to the same UV dose as the membranes in hydrogel (XP solution), and obtained lifetimes ranging from $30 \mathrm{~min}$ to $34.8 \mathrm{hr}$. This is below the minimum lifetime obtained for DPhPE-A in X1000P, and indicates that the increased longevity of the DPhPE-A membranes is caused by the presence of encapsulating hydrogel.

In order to assess whether the hydrogel encapsulation affected BLM properties, we measured conductance $G$ and capacitance $C$ as described previously ${ }^{[27]}$. Membrane conductance ranged from 115 to $220 \mathrm{nS}$ and membrane capacitance ranged from 1560 to $3950 \mathrm{pF}$ with no significant differences between hydrogel-encapsulated membranes and freestanding membranes (see Fig. 4). This shows that encapsulation of the membranes does not change their characteristics. The capacitance values correspond to an overall specific membrane capacitance of $0.035-0.088 \mu \mathrm{F} \mathrm{cm}^{-2}$ (assuming that the total membrane area was equal to the area of the aperture array, $0.045 \mathrm{~cm}^{2}$ ), which is

Table 5. Lifetimes of DPhPC and DPhPE-A lipid membranes in buffer or encapsulated in X1000P hydrogel. The minimum and maximum observed lifetimes of membranes are given. The success rate (success = survival of the membrane for at least $12 \mathrm{hr}$ ) for these membranes is indicated as the number of successful membranes out of the total number of membranes formed

\begin{tabular}{|cclccc|} 
Sample & $\begin{array}{l}\text { UV time } \\
(\mathrm{min})\end{array}$ & Lipid & $\begin{array}{c}t_{\min } \\
(\mathrm{hr})\end{array}$ & $\begin{array}{c}t_{\max } \\
(\mathrm{hr})\end{array}$ & $S_{(\mathrm{t}>12 \mathrm{hr})}$ \\
\hline Buffer & None & DPhPC & 0.02 & 20.8 & $2 / 6$ \\
& & DPhPE-A & 0.6 & 19.8 & $2 / 5$ \\
XP & 15 & DPhPE-A & 0.6 & 37.8 & $2 / 5$ \\
X1000P & 15 & DPhPC & 0.8 & 34.8 & $1 / 2$ \\
& & DPhPE-A & 47.3 & 219.1 & $3 / 3$ \\
\hline
\end{tabular}



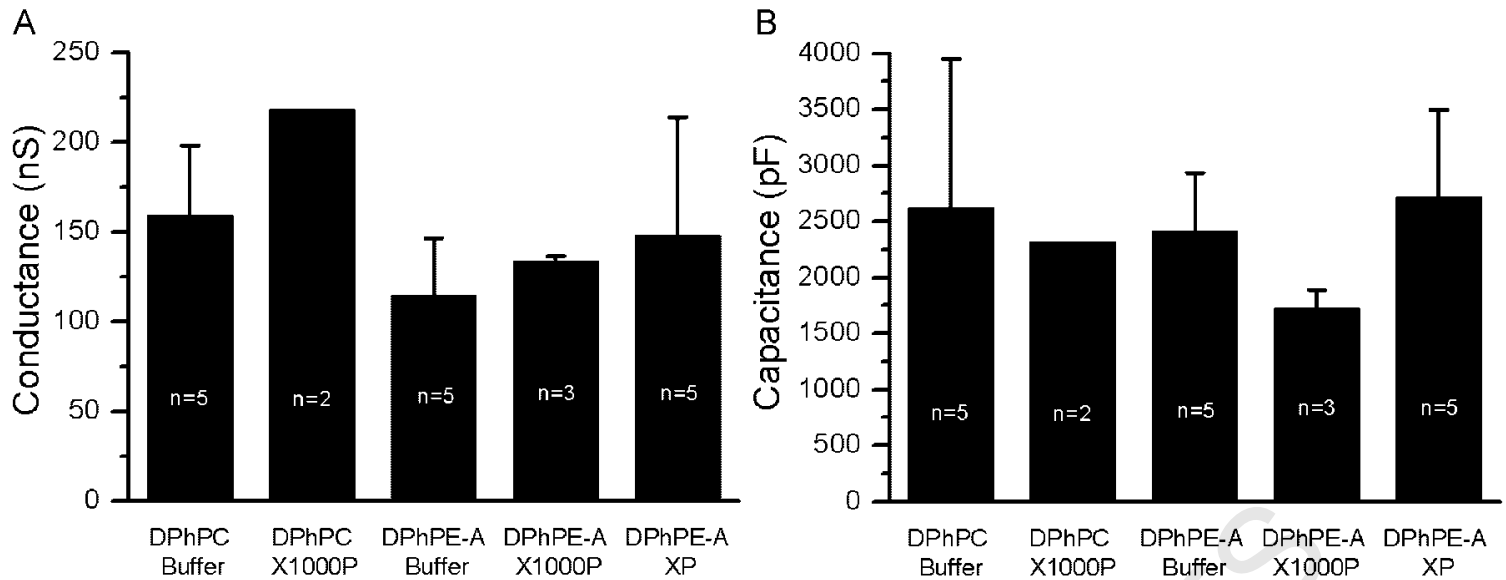

Figure 4. Freestanding X1000P-encapsulated BLM electrical properties. (a): conductance G (b): capacitance C. Mean $\pm \mathrm{sd}$ values of each membrane were determined using the methods described in Ref. ${ }^{[26]}$ after 50 min for membranes with lifetime $>60$ min or the last 10 min for membranes with lifetime $<60 \mathrm{~min}$.

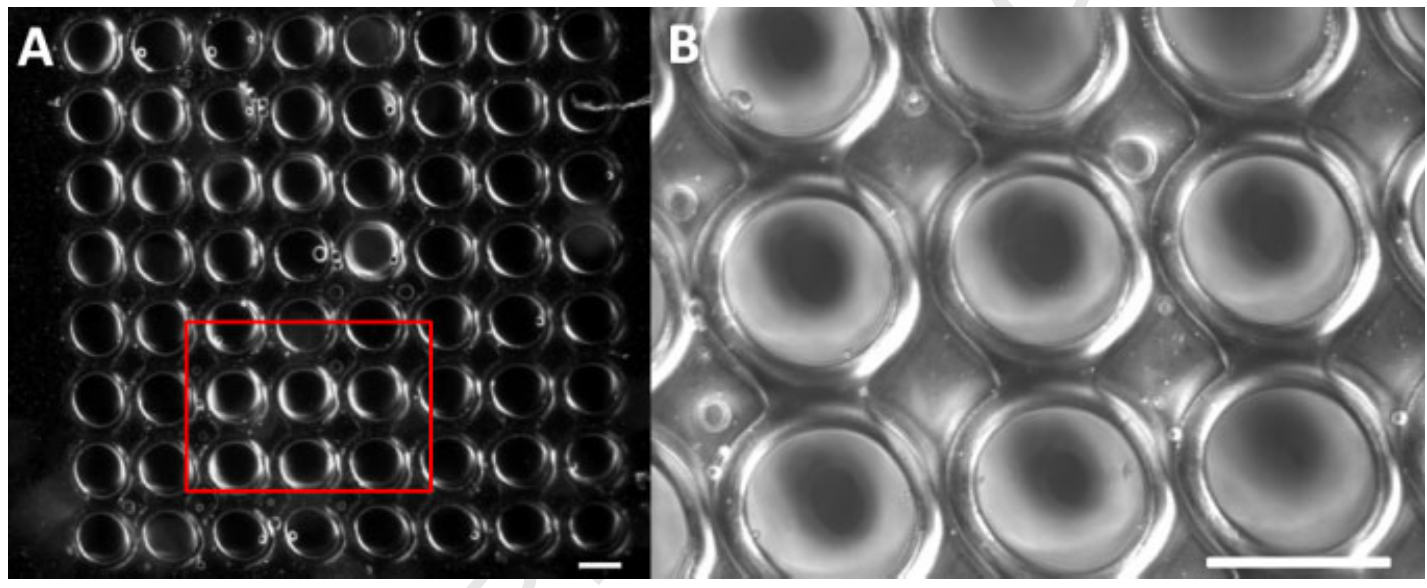

Figure 5. Optical microscope images of a hydrogel-encapsulated lipid membrane obtained as described in Ref. ${ }^{[26]}$. (a): The entire $8 \times 8$ array. (b): magnified image of the apertures in the red square in (a), showing lipid membranes with clearly recognizable Plateau-Gibbs borders (light annular regions). Scale bar $300 \mu \mathrm{m}$.

much lower than the specific capacitance for fully thinned solvent-containing membranes $\left(0.4-0.6 \mu \mathrm{F} \mathrm{cm}^{-2}\right)$ reported in the literature $^{[33]}$. The low specific overall capacitance value measured does not preclude the existence of bilayer patches, but if they exist they only constitute $9-22 \%$ of the total aperture area and the rest of the aperture array area has solvent-containing lipid patches. This is consistent with the bright field image of the $8 \times 8$ arrays where the Plateau-Gibbs borders ${ }^{[34]}$ with large annuli are clearly visible (see Fig. 5). Of course, an optimized thinning of the BLMs would increase the effective bilayer area. On the other hand this would also tend to make membranes even more unstable before crosslinking. Thus we are faced with a compromise between larger bilayer areas and reasonable BLM formation success rates and lifetimes.

\section{Functionality of encapsulated BLMs}

In order to verify that we have areas where the lipid bilayer thickness is compatible with the hydrophobic spanning segments of transmembrane proteins, we incorporated the channel-forming peptide gramicidin A into the BLMs followed by X1000P encapsulation (see Fig. 6).

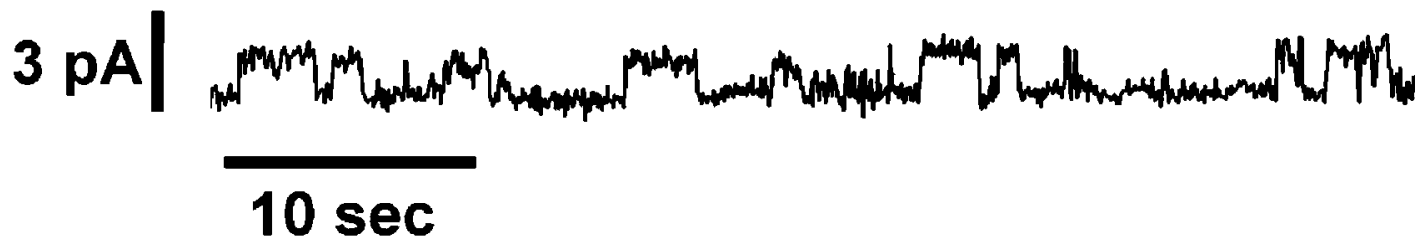

Figure 6. Single channel gramicidin current trace from an X1000P-encapsulated 5 day old DPhPE-A membrane in buffer adjusted to $1 \mathrm{M} \mathrm{KCl}$. A $60 \mathrm{mV} \mathrm{DC}$ potential was applied across the membrane and the signal was filtered at $10 \mathrm{~Hz}$. 
Current trace recordings showed single channel events with current amplitudes around $2 \mathrm{pA}$, corresponding to a single channel conductance of $33 \mathrm{pS}$, consistent with previous results for gramicidin in $1 \mathrm{M} \mathrm{KCl}^{[35]}$. The current trace recordings confirmed functional reconstitution of gramicidin ion channels, which strongly suggested that functional lipid bilayer areas are present in the X1000P-encapsulated and stabilized membranes.

\section{CONCLUSION}

Hydrogels show promise as materials for encapsulating biomimetic membranes. They have volumetric stability and their nano-scale cut-off sizes and water flux properties make them promising in biomimetic devices where they can support the biomimetic membranes and yet allow vectorial flux of matter to (and through) the biomimetic membrane. We have demonstrated that multi-aperture arrays of membranes can be successfully encapsulated and that it is possible to create a robust biomimetic membrane in which proteins can be reconstituted. However, the main challenge still remains: how to improve the stability of the membranes in the HPS before crosslinking and to ensure that protein function is not compromised by maneuvers used to crosslink the hydrogels.

\section{Acknowledgements}

We thank Kamila Pszon for preparing Fig. 1. This work was supported through MEMBAQ, a Specific Targeted Research Project (STREP), by the European Commission under the Sixth Framework Programme (NMP4-CT-2006-033234), by the Danish National Advanced Technology Foundation (023-2007-1) and by a grant to DTU Physics from the Danish National Research Foundation.

\section{REFERENCES}

[1] C. H. Nielsen, 2009, Biomimetic membranes for sensor and separation applications. Anal. Bioanal. Chem. 395: 697-718.

[2] E. Sackmann, M. Tanaka, 2000, Supported membranes on soft polymer cushions: fabrication, characterization and applications. Trends Biotechnol. 18: 58-64.

[3] E. Reimhult, K. Kumar, 2008, Membrane biosensor platforms using nano- and microporous supports. Trends Biotechnol. 26: 82-89.

[4] J. Jagur-Grodzinski, 2009, Polymeric gels and hydrogels for biomedical and pharmaceutical applications. Polym. Adv. Technol. 21: 27-47.

[5] C. H. Nielsen, Lipid-protein interactions in biomembranes. in Handbook of Molecular Biophysics (Eds. H. G. Bohr), Wiley, Berlin, 2009, 329-358.

[6] F. N. R. Petersen, I. Laursen, H. Bohr, C. H. Nielsen, 2009, Proteiing. Biochem. Biophys. Res. Commun. 387: 760-765.

[7] F. N. R. Petersen, C. H. Nielsen, 2009, Raman spectrosocpy as a tool for investigating lipid protein interactions. Spectroscopy 24: 26-35.

[8] H. Ti Tien, 1974, Bilayer lipid membranes (BML) Theory and practice. Marcel Dekker Inc, New York

[9] H. T Tien, A. Ottova-Leitmannova, (Eds.) Planar Lipid Bilayers (BLMs) and Their Applications. Elsevier, Amsterdam, 2003. Drug Delivery Rev. 54: 3-12. $\mathrm{n}$-induced bilayer perturbations: lipid ordering and hydrophobic match-

[10] A. S. Hoffman, 2002, Hydrogels for biomedical applications. Adv.
[11] N. A. Peppas, Y. Huang, M. Torres-Lugo, J. H. Ward, J. Zhang, 2000, Physicochemical foundations and structural design of hydrogels in medicine and biology. Annu. Rev. Biomed. Eng. 2: 9-29.

[12] N. A. Peppas, P. Bures, W. Leobandung, H. Ichikawa, 2000, Hydrogels in pharmaceutical formulations. Eur. J. Pharm. Biopharm. 50: 27-46.

[13] T. J. Jeon, N. Malmstadt, J. J. Schmidt, 2006, Hydrogel-encapsulated lipid membranes. J. Am. Chem. Soc. 128: 42-43. bilayer membranes anchored to an in situ polymerized hydrogel. Adv. Mater. 20: 84-89.

[15] J. W. Shim, L. Q. Gu., 2007, Stochastic sensing on a modular chip

[16] X. F. Kang, S. Cheley, A. C. Rice-Ficht, H. Bayley, 2007, A storable encapsulated bilayer chip containing a single protein nanopore. J. Am. Chem. Soc. 129: 4701-4705.

[17] R. F. Costello, I. R. Peterson, J. Heptinstall, N. G. Byrne, L. S. Miller, 1998, A robust gel-bilayer channel biosensor. Adv. Mater. Opt. Electron. 8: 47-52.

[18] R. F. Costello, I. R. Peterson, J. Heptinstall, D. J. Walton, 1999, Improved gel-protected bilayers. Biosens. Bioelectron. 14: 265-271.

[19] J. A. Beddow, I. R. Peterson, J. Heptinstall, D. J. Walton, 2004, Reconstitution of nicotinic acetylcholine receptors into gel-protected lipid membranes. Anal. Chem. 76: 2261-2265.

[20] H. T. Tien, A. L. Ottova, 1998, Supported planar lipid bilayers (s-BLMs) as electrochemical biosensors. Electrochim. Acta 43: 3587-3610.

[21] W. Ziegler, J. Gaburjakova, M. Gaburjakova, B. Sivak, V. Rehacek, V. Tvarozek, T. Hianik, 1998, Agar-supported lipid bilayers - basic structures for biosensor design. Electrical and mechanical properties. Colloids Surf., A 140: 357-367.

[22] T. Baumgart, A. Offenhausser, 2003, Polysaccharide-supported planar bilayer lipid model membranes. Langmuir 19: 1730-1737.

[23] M. Uto, M. Araki, T. Taniguchi, S. Hoshi, S. Inoue, 1994, Stability of an agar-supported bilayer lipid membrane and its application to a chemical sensor. Anal. Sci. 10: 943-946.

[24] J. R. Hazel, 1988, Homeoviscous adaptation in animal cell membranes. Physiol. Regul. Membr. Fluidity 149-188.

[25] Ed., T. E Creighton, 1993, Proteins, Structures and Molecular Properties, 2nd Ed., New York ${ }^{\mathrm{Q} 2}$.

[26] J. S. Hansen, M. Perry, J. Vogel, J. Groth, T. Vissing, M. Larsen, O. Geschke, J. Emneus, H. Bohr, C. H. Nielsen, 2009, Large scale biomimetic membrane arrays. Anal. Bioanal. Chem. 395: 719-727.

[27] M. Perry, T. Vissing, T. P. Boesen, J. S. Hansen, J. Emneus, C. H. Nielsen, 2009, Automated sampling and data processing derived from biomimetic membranes. Bioinspir. Biomim. 4: 44001.

[28] J. Vogel, M. E. Perry, J. S. Hansen, P-Y. Bollinger, C. H. Nielsen, O. Geschke, 2009, Support structure for biomimetic applications. J. Micromech. Microeng. 19: 025026.

[29] J. S. Hansen, M. E. Perry, J. Vogel, T. Vissing, O. Geschke, J. Emneus, C. $\mathrm{H}$. Nielsen, 2009, Development of an automation technique for the establishment of functional lipid bilayer arrays. J. Micromech. Microeng. 19: 025014.

[30] M. Mulder, 1996, Basic Principles of Membrane Technology. Kluwer Academic Publishers, Dordrecht.

[31] P. Szewczykowski, 2009, Nano-porous materials from diblock copolymers and their membrane application. PhD Thesis. In Department of Chemical and Biochemical Engineering. Technical University of Denmark, Lyngby. Reverse osmosis desalination: water sources, technology, and today's challenges. Water Res. 43: 2317-2348.

[33] R. Benz, O. Fröhlich, P. Läuger, M. Montal, 1975, Electrical capacity of black lipid films and of lipid bilayers made from monolayers. Biochim. Biophys. Acta 394: 323-334.

[34] S. H. White, 1970, A study of lipid bilayer membrane stability using precise measurements of specific capacitance. Biophys. J. 10: 1127-1148. [35] O. S. Andersen, 1983, Ion movement through gramicidin A channels. Single-channel measurements at very high potentials. Biophys. J. 41: 119-133.
[14] N. Malmstadt, T-J. Jeon, J. J. Schmidt, 2008, Long-lived planar lipid containing a single-ion channel. Anal. Chem. 79: 2207-2213.

[32] L. F. Greenlee, D. F. Lawler, B. D. Freeman, B. Marrot, P. Moulin, 2009, 


\section{Author Query Form (PAT/1850)}

Special Instruction: Author please include responses to queries with your other corrections and return by e-mail.

Q1: Author: You have provided one figure in color. Because of the high cost of color printing we can only print the figure in color if authors cover the expense. However, the figure will be published online in color free of cost. Please confirm if you would like the figure to be printed in color Q2: Author: Please provide publisher name. 


\section{WILEY AUTHOR DISCOUNT CLUB}

We would like to show our appreciation to you, a highly valued contributor to Wiley's publications, by offering a unique $\mathbf{2 5} \%$ discount off the published price of any of our books*.

All you need to do is apply for the Wiley Author Discount Card by completing the attached form and returning it to us at the following address:

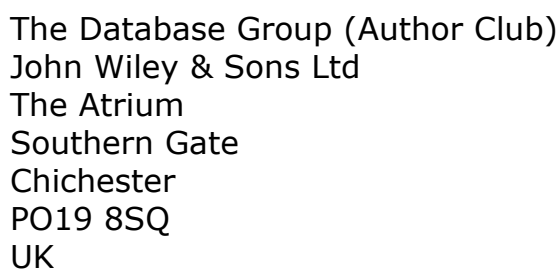

Alternatively, you can register online at www.wileyeurope.com/go/authordiscount Please pass on details of this offer to any co-authors or fellow contributors.

After registering you will receive your Wiley Author Discount Card with a special promotion code, which you will need to quote whenever you order books direct from us.

The quickest way to order your books from us is via our European website at:

\section{http: / / www.wileyeurope.com}

Key benefits to using the site and ordering online include:

- Real-time SECURE on-line ordering

- Easy catalogue browsing

- Dedicated Author resource centre

- Opportunity to sign up for subject-orientated e-mail alerts

Alternatively, you can order direct through Customer Services at:

cs-books@wiley.co.uk, or call +44 (0)1243 843294, fax +44 (0)1243843303

So take advantage of this great offer and return your completed form today.

Yours sincerely,

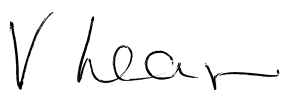

Verity Leaver

Group Marketing Manager

author@wiley.co.uk

This offer is exclusive to Wiley Authors, Editors, Contributors and Editorial Board Members in acquiring books for their personal use. There must be no resale through any channel. The offer is subject to stock availability and cannot be applied retrospectively. This entitlement cannot be used in conjunction with any other special offer. Wiley reserves the right to amend the terms of the offer at any time. 


\section{REGISTRATION FORM For Wiley Author Club Discount Card}

To enjoy your $25 \%$ discount, tell us your areas of interest and you will receive relevant catalogues or leaflets from which to select your books. Please indicate your specific subject areas below.

Accounting

- Public

- Corporate

\section{Chemistry}

- Analytical

- Industrial/Safety

- Organic

- Inorganic

- Polymer

- Spectroscopy

Encyclopedia/Reference

- Business/Finance

- Life Sciences

- Medical Sciences

- Physical Sciences

- Technology

\section{Earth \& Environmental Science}

Hospitality

- Bioinformatics/ Computational Biology

- Proteomics

- Genomics

- Gene Mapping

- Clinical Genetics

[]
[]
[]

[ ] $]$

[ ]

[ ]

[]

$[$ ]

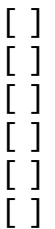

]

[]<smiles></smiles>

\section{Medical Science}

- Cardiovascular

- Diabetes

- Endocrinology

- Imaging

- Obstetrics/Gynaecology

- Oncology

- Pharmacology

- Psychiatry
Architecture

[ ]

Business/Management

Computer Science

- Database/Data Warehouse

[ ]

- Internet Business

- Networking

- Programming/Software Development

- Object Technology

[ ]

[

[ ]

Engineering

- Civil

- Communications Technology

- Electronic

- Environmental

- Industrial

- Mechanical

[

[]

[]

Finance/Investing

- Economics

- Institutional

- Personal Finance

Life Science

Landscape Architecture

Mathematics

Statistics

\section{Manufacturing}

Materials Science

Psychology

- Clinical

- Forensic

- Social \& Personality

- Health \& Sport

- Cognitive

- Organizational

- Developmental \& Special Ed

- Child Welfare

- Self-Help

Physics/Physical Science 
I confirm that I am (*delete where not applicable):

WILEY

a Wiley Book Author/Editor/Contributor* of the following book(s):

ISBN:

ISBN:

a Wiley Journal Editor/Contributor/Editorial Board Member* of the following journal(s):

Date:

\section{PLEASE COMPLETE THE FOLLOWING DETAILS IN BLOCK CAPITALS:}

TITLE: (e.g. Mr, Mrs, Dr) FULL NAME:

JOB TITLE (or Occupation):

DEPARTMENT:

COMPANY/INSTITUTION:

ADDRESS:

TOWN/CITY:

COUNTY/STATE:

COUNTRY:

POSTCODE/ZIP CODE:

DAYTIME TEL:

FAX:

E-MAIL:

\section{YOUR PERSONAL DATA}

We, John Wiley \& Sons Ltd, will use the information you have provided to fulfil your request. In addition, we would like to:

1. Use your information to keep you informed by post of titles and offers of interest to you and available from us or other Wiley Group companies worldwide, and may supply your details to members of the Wiley Group for this purpose.

[ ] Please tick the box if you do NOT wish to receive this information

2. Share your information with other carefully selected companies so that they may contact you by post with details of titles and offers that may be of interest to you.

[ ] Please tick the box if you do NOT wish to receive this information.

\section{E-MAIL ALERTING SERVICE}

We also offer an alerting service to our author base via e-mail, with regular special offers and competitions. If you DO wish to receive these, please opt in by ticking the box [ ].

If, at any time, you wish to stop receiving information, please contact the Database Group (databasegroup@wiley.co.uk) at John Wiley \& Sons Ltd, The Atrium, Southern Gate, Chichester, PO19 8SQ, UK.

TERMS \& CONDITIONS

This offer is exclusive to Wiley Authors, Editors, Contributors and Editorial Board Members in acquiring books for their personal use. There should be no resale through any channel. The offer is subject to stock availability and may not be applied retrospectively. This entitlement cannot be used in conjunction with any other special offer. Wiley reserves the right to vary the terms of the offer at any time. 